\title{
The Interaction Model in iLearning Environments and its Use in the Smart Lab Concept
}

\author{
http://dx.doi.org/10.3991/ijoe.v7i4.1793 \\ Y. Lyalina ${ }^{1}$, R. Langmann ${ }^{2}$ and V. Krisilov ${ }^{1}$ \\ ${ }^{1}$ Odessa National Polytechnic University, Odessa, Ukraine \\ 2 Dusseldorf University of Applied Sciences, Dusseldorf, Germany
}

\begin{abstract}
This paper identifies and discusses current trends and challenges, offers an overview of state-of-the-art technologies in the development of remote and smart laboratories, and introduces the iLearning interaction model. The use of the model allows reconstructing alreadyexisting iLearning environments. The smart lab model is described for face-to-face, Mobile and Blended Learning. As a result, this allows offering new information technology that organizes the educational process according to learning type (face-to-face, hands-on learning, Life Long Learning, E-Learning, M-Learning, Blended learning, Game-based learning, etc.). The remote access Architecture and Interface for the multifunctional Smart Lab will be developed.
\end{abstract}

Index Terms-blended learning, educational process, iLearning, LMS, smart lab, web-based learning.

\section{INTRODUCTION}

During the last few decades, remote and smart laboratories have been introduced into engineering education processes and integrated within e-learning frameworks offered to engineering and science students. Remote laboratories are also being used to support lifelong learning and student's independent learning activities [1].

This way, learners can access real experiments around the clock from anywhere via Internet. As the experiments are real and are only carried out remotely, learners still have the feeling of being present at the hands-on laboratory session. Remote experimentation client applications are often integrated into learning management systems (LMS) supporting the courses, students and content. However, such environments are not suitable to support real-time experiments. For this purpose, it is necessary to use special Remote or Smart Labs.

A remote laboratory is a software and hardware system that enables students to use real experiments physically located at the university [2].

Smart laboratories are special mobile labs that possess features such as capability, elaboration, cuteness and cleverness (i.e., can also work also as a remote lab in LAN and WAN). Smart labs can be used for distance, face-to-face and blended learning. The results of current research show the need for collaborative learning integration. Remote and smart virtual laboratories have become a good solution in higher education curricula [3]. On the other hand, there is currently an insufficient number of adapted standards for remote or smart labs and virtual experimentation. This trend shows that both traditional and virtual (Web 2.0) solutions will continue to exist during the coming years, revealing the benefits of not only face-to face but all kinds of Internet-based Learning (iLearning) also known as E-learning.

Nowadays, students and schoolchildren must learn an increasing amount of information during the educational process. The amount of technical information currently doubles every two years. Lack of study time forces reorganization of the educational process toward self-directed study, E-Learning, Life Long Learning and Mobile Learning. All these educational types can be described as iLearning or Internet Learning. The definition of iLearning includes not only all types of E-Learning but also Mobile, Blended, Remote Learning and so on, where Internet technologies are used.

The new educational paradigm has enabled rapid development of mobile and remote laboratories for hands-on and distance learning. In the last few years, they have become widely used not only in E-learning educational processes but also to support traditional learning. The purpose of smart lab use is to reach more educational skills and targets in less time. The state of the art has demonstrated many new learning trends with the application of complex technical systems: training in a virtual factory (Second Life - eMotions Factory); learning in a coupled virtual environment (Hyper-Bond-Concept), and communication of virtual realities by means of video, remote labs, and smart labs. These trends also affect the continuing education program.

The smart device paradigm is used to describe devices that have enough built-in intelligence to perform actions independently. Physically, it is equivalent to a classical remote device combined with a server application [4].

According to the smart device paradigm, a device can be called "smart" if it:

- is online, intelligent, independent and networked, such as sensors and actuators;

- integrates hardware and software, as well as advanced and versatile communication capabilities;

- supports remote identification, initialization, control and diagnostics;

- interprets incoming requests and adapts responses using low- or high-level protocols.

The smart device paradigm successfully describes the new way of developing the server-side aspect of remote laboratories [4].

For the specified purpose, the modern skills that learners must possess on course completion must be summarized. To the "engineering" and professional skills that 
students have attained at the end of the course are added such skills as:

- critical thinking

- problem solving

- creativity and innovation

- adaptability

- collaboration

- communication (written, oral, and blended and advanced media)

- information sourcing and media literacy

- self-direction and self-assessment

- application of technology to workflow [5]

The given skills should be acquired during the iLearning process independent of the course theme.

The current research is being carried out under the $\mathrm{PhD}$ work in DUAS.

As a result, new information technology will be offered to organize the educational process according to learning type (face-to-face hands-on learning, Life Long Learning, E-Learning, M-Learning, Blended learning, Game-based learning etc). The multifunctional Smart Lab remote access Architecture and Interface will be developed.

It will allow the use of not only the traditional learning types (face-to-face, game-based) but also of E-Learning methodologies (M-learning, Blended Learning etc) in the technical fields. It is expected that this technology will essentially improve the quality of each learning type by decreasing the training time and increasing the quantity of training goals reached for the same time interval. It will allow formalizing the choice of the given material, depending on the type of educational process. The smart device paradigm will be used in the research.

\section{INTERACTION MODEL IN ILEARNING}

Most existing Web-based learning environments are founded on basic instruction models. Their main functionalities are centered on the management and distribution of learning materials, synchronous and asynchronous communication, and progress tracking and reporting. Some of them address collaborative learning. However, most of such learning environments do not effectively support collaboration models used in modern working life [6].

Much research has been focused on e-learning technologies, and many presentations have been made on accessibility, interoperability, durability, and reusability of components [7]. A Web service-oriented framework also gives flexibility to the LMS design and hides the implementation complexity from programmers, thus speeding up the design process. Applying Web service technologies to a SCORM-compatible LMS simplifies its implementation and maintenance and offers service consumers more choices in finding the service they require [7]. An in-depth review of a wide number of LMSs on the market can be found in [8], where a guide to choosing among their functionalities is also provided.

The objectives of the current research can be defined as follows:

- to improve the quality of each learning type by decreasing the training time and simultaneously increasing the learning outcomes for the same time interval.
- to encourage young people and students to study modern technical subjects such as industrial automation and communication technologies using modern technical devices (Smart Labs, Smart phones) for learning purposes.

The interaction between the learning object and subject during all types of iLearning can be defined as an informational process characterized by data transmission (readings, practice etc), repository (the learner memorizes the information) and acquisition (the learner stores the information and uses it at the appropriate moment) (Fig. $1)$.

If we know the specific targets of the educational process, it is easy to structure the material according to the specified targets. In this case, each iLearning process can be presented as a 4-layer reference interaction model (Fig. 2).

The first layer (STRUCTURE) indicates the courses with their contents. The second layer (SEANS) includes the description of all interactions between the learning object and subject (tests, communication, course map, etc). Here the material can be divided into portions, defined by each type of iLearning (i.e. M-Learning learning atoms etc.). The third layer (TRANSPORT) describes how the learner receives the data (materials, lectures, etc.). The fourth layer (CONTACT) describes the standards for each type of iLearning. This model is adaptive. Each layer can be changed easily for each type of iLearning without any changes in the other layers. Such

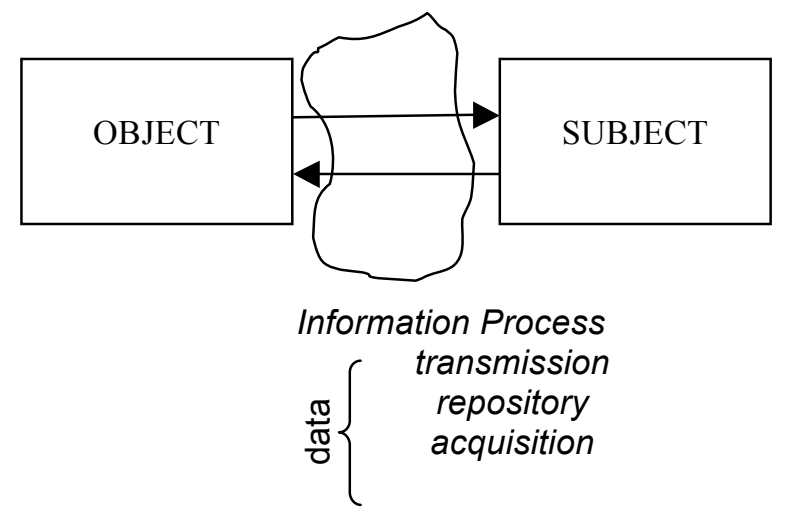

Figure 1. Learning object and subject interaction model.

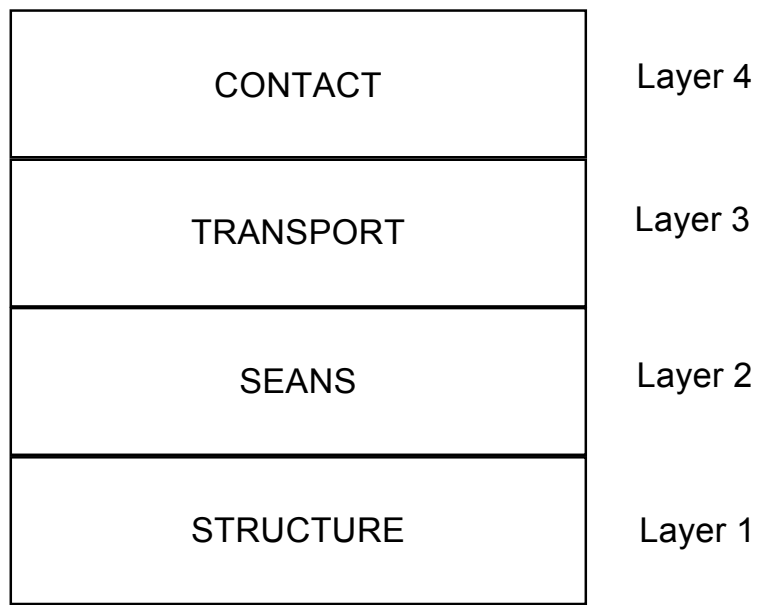

Figure 2. Reference model of the 4 layers of interaction in iLearning 
a model can be used for any type of LMS for different kinds of learning. It means that already-existing ELearning systems can be easily reconstructed for $\mathrm{M}$ Learning or individual learning environments.

With this model, the content can be structured according to the targets for each learning type. Each learning course can also be presented as a graph with the targets in the knots. By changing the learning process targets and analyzing this graph, the structure layer (Layer 1) can be changed. On this layer, the material can be divided into portions. Here we can choose the amount of information that should be given to each type of ILearning. Moreover, as the quantity of information increases up to $20 \%$ each 5 years, use of such a model makes it easy to count the speed of information change and the amounts of each information portion that should be given to attain the best educational results.

\section{SMART LAB MODEL}

Under the research PhD work in Dusseldorf University of Applied Sciences, it is planned to develop the special smart lab to carry out the interactive experimentations in the automation field by accessing and controlling real instruments.

The current trend in engineering curricula applies the concept of remote learning . The smart lab will consist of $\mathrm{n}$ remote labs (Fig. 3). Each remote lab can also work alone as a standby application.

For this model, the concept of the 4 layers of interaction in iLearning will be used. The main idea is that each remote lab can also be used for Smartphone-based mobile learning as it consists of $\mathrm{n}$ learning atoms. Each learning atom covers one of the basic industrial automation topics and is specified for no more than 15-20 minutes of study including the theory and brief practical exercise with access to the remote lab.

The smart lab concept could be applied to the existing remote and virtual labs to divide them by components according to the iLearning interactions reference model.

The use of such a Smart Lab fully proves the "learning by doing" concept in all types of iLearning. Such smart labs can be a useful complementary educational resource for hands-on-labs as they allow remote monitoring or supervision of an on-going experiment.

The Smart Lab is required for use in the network operating mode. For this purpose, all training software, programming software and examples can run in a remote environment on an HTML page, i.e., in a remote desktop applet (VNC).

The remote display of the experiments is improved by means of video cameras and video-streaming technologies fully supported by modern Smartphones. During mobile learning, access to the main lab is very brief, which gives the possibility to train more students.

One of the existing examples of such a smart lab, used for face-to-face study, as a remote lab and for M-Learning and E-learning, is the CoNeT Mobile Lab - CML developed under the CoNeT Project in DUAS (2009-2011) [9]. A wide range of experiments can work simply on the mobile device.

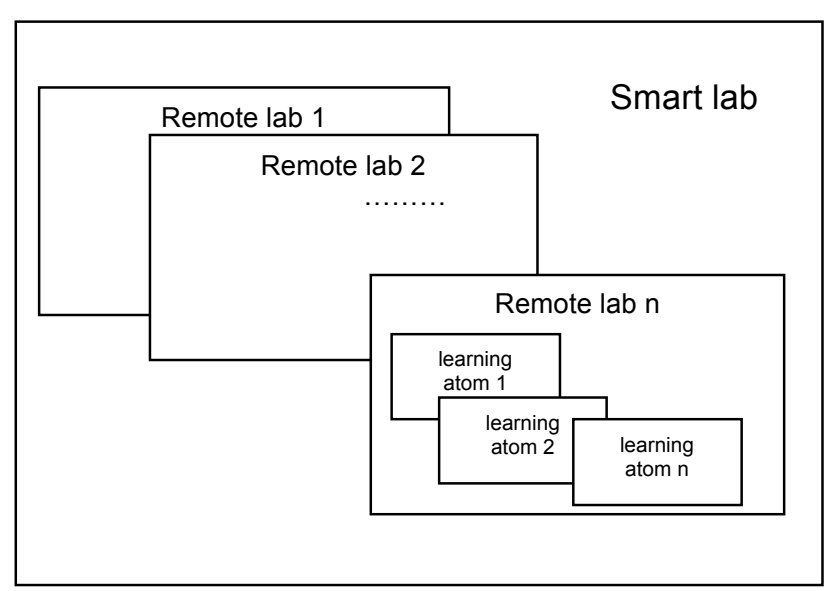

Figure 3. Model of the smart lab.

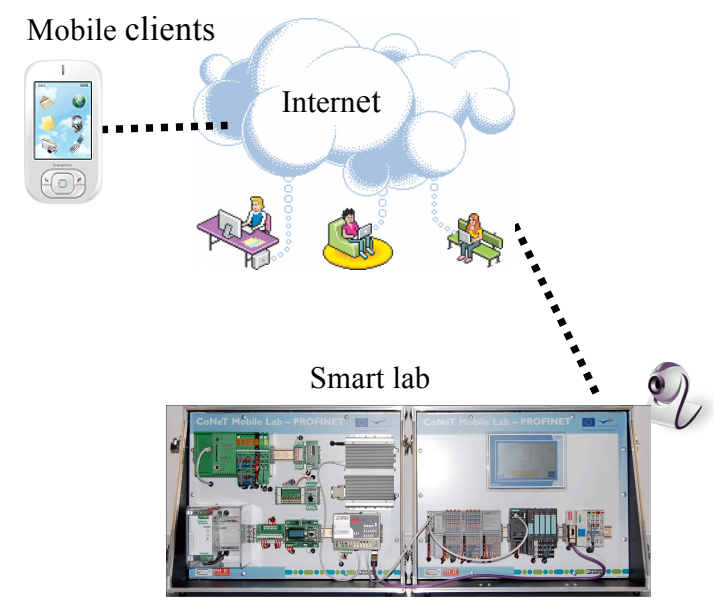

Figure 4. View of the CML smart lab

Figure 4 shows the layers of the smart lab:

- Mobile clients' software (with remote access)

- Physical CML equipped with a web cam. [10]

For the mobile concept, practical exercises are divided into minute parts known as learning atoms. One of the extensions of the smart lab use for M-Learning can also be Augmented Reality. Augmented reality (AR) is a term for a live direct or indirect view of a physical, real-world environment whose elements are augmented by computergenerated sensory input, such as sound or graphics. It is related to a more general concept called mediated reality in which a view of reality is modified (possibly even diminished rather than augmented) by a computer. As a result, the technology functions by enhancing one's current perception of reality. In contrast, virtual reality replaces the real world with a simulated one.

The Smart Lab can be used for both face-to-face teaching and for all kinds of iLearning by easily changing the 4 interaction layers. Moreover, the individual training modes can be set by use of this model.

This model is reconfigurable and adaptive and can be used on different levels of interaction with the object and subject of the teaching process. 


\section{CONCLUSION}

The proposed learning concept allows providing all kinds of learning, including traditional face-to-face and Distance learning and also offers possibilities for further development of Mobile learning, which is rapidly spreading in all fields of education. Smart tools such as Smart Labs are very useful to support the process of understanding and learning by doing. The proposed interaction model in iLearning environments can be used to describe each type of iLearning. The model is adaptive; each layer can be easily changed for each type of iLearning without any changes in the other layers. The innovative methodologies used for the Smart Lab model include all kinds of iLearning, hands-on training (learning by doing) and are strongly focused on real work situations and not on theoretical examples or exercises. Project Based Learning and Problem Based Learning will be used for iLearning methodologies such as remote labs, M-Learning and web-based exercises.

\section{ACKNOWLEDGMENTS}

Phoenix Contact Deutschland $\mathrm{GmbH}$ for the support in research and development and for the great support in CML 3 equipment (PROFINET on Phoenix Contact Platform)

This research is carried out at the Dusseldorf University of Applied Sciences (DUAS) in cooperation with ONPU (Odessa National Polytechnic University, Ukraine)

This work was supported by EU project Co-operative Network Training (CoNeT), project number: 5021066LLP-1-2009 1-BE-ERASMUS-ECU - Lifelong learning program, ERASMUS cooperation between Higher Education Institutions and Enterprises, October 2009- September 2012

\section{REFERENCES}

[1] Current Trends in Remote Laboratories; Luis Gomes, Seta Bogosyan; IEEE Transactions on Industrial Electronics, Vol. 56, no. 12, December 2009; pp. 4744-4756; ISSN: 0278-0046, http://dx.doi.org/10.1109/TIE.2009.2033293

[2] Pablo Orduña, Javier Garcia-Zubia, Jaime Irurzun, Diego Lópezde Ipiña, Luis Rodriguez-Gil Enabling mobile access to remote la- boratories: IEEE Global Engineering Education Conference (EDUCON) April 4-6, 2011 Amman, Jordan pp. 312-317

[3] Ch. Salzman, D. Gillet Remote labs and Social Media: IEEE Global Engineering Education Conference (EDUCON) April 4-6, 2011 Amman, Jordan pp. 312-317

[4] Denis Gillet, Christophe Salzmann "Social Media \& Smart Devices," IEEE Global Engineering Educational Conference (EDUCON) - April 4-6, 2011, Amman, Jordan, pp. 307-311.

[5] S. Rapuano, F. Zoino "A Learning Management System Including Laboratory Experiments on Measurement Instrumentation," IEEE Transactions on instrumentation and measurement, Vol. 55, No. 5, October 2006, pp. 175-177. http://dx.doi.org/10.1109/TIM.2006.880309

[6] H. Batatia, A. Ayache, H. Markkanen, "Netpro: An innovative approach to network project based learning," in Proc. ICCE, Auckland, New Zealand, 2002, pp. 382-386.

[7] C. P. Chu, C. P. Chang, C. W. Yeh, and Y. F. Yeh, "A webservice oriented framework for building SCORM compatible learning management systems," in Proc. ITCC, Las Vegas, NV, 2004, vol. 1, pp. 156-161.

[8] B. Chapman, "In-Depth Profiles of 50 Learning Management Systems, with Custom Comparison Across 200+ Features," 2004, Sunnyvale, CA: Brandon Hall. [Online]. Available: www.brandon-hall.com

[9] Lifelong learning program application, ERASMUS Co-operation between Higher Education Institutions and Enterprises, 502106LLP-1-2009-1-BE- ERASMUS-ECUE: CoNeT: Co-operative Network Training, October 2009 - September 2012.

[10] Y. Lyalina, R.Langmann, O.Makarov, "Smart Labs for remote experimentation in communication technologies," REV 2011 proceedings, Brasov, Romania 29 June -02 July 2011, pp. 47-50

\section{AUTHORS}

Y. Lyalina is with the Odessa National Polytechnic University, Pr. Schewtchenko 1, 65044, Odessa, Ukraine (e-mail: yuliya.lyalina@fh-duesseldorf.de).

R. Langmann is with the Dusseldorf University of Applied Sciences, Josef-Gockeln-Str. 9 40474, Dusseldorf, Germany (e-mail: reinhard.langmann@fh-duesseldorf.de).

V. Krisilov is with the Odessa National Polytechnic University, Pr. Schewtchenko 1, 65044, Odessa, Ukraine, (e-mail: krissilovva@mail.ru)

This article is a modified version of a paper presented at the International Conference ICBLManuscript received 18 August 2011. Published as resubmitted by the authors 26 October 2011. 